\title{
Edremit Körfezi’nde Dağılım Gösteren Beş Kırlangıç Balığı (Triglidae) Türünün Besin
} Tercihleri

\section{Dilek İLHAN}

Ege Üniversitesi, Su Ürünleri Fakültesi, İzmir.

Sorumlu Yazar: dilek.ilhan@ege.edu.tr

Araştırma Makalesi

Geliş 20 Şubat 2019; Kabul 22 Mayıs 2019; Basım 15 Eylül 2019.

Alıntılama: İlhan, D. (2019). Edremit Körfezi’nde dağılım gösteren beş kırlangıç balığ1 (Triglidae) türünün besin tercihleri. Acta Aquatica Turcica, 15(3), 347-353. https://doi.org/10.22392/actaquatr.529907

\section{Özet}

Bu çalışmada, Eylül 1999-Ağustos 2000 tarihleri arasında Edremit Körfezi (Ege Denizi)'nden trol örneklemeleri ile toplanan beş kırlangıç balığı türünün (Chelidonichthys lucerna, Chelidonichthys lastoviza, Eutrigla gurnarduss, Lepidotrigla cavillone, Trigla lyra) besin kompozisyonu araştırılmıştır. Toplamda 1205 adet bireye ait mide içeriği (262 C.lucerna, 300 C. lastoviza, 300 E. gurnardus, 300 L. cavillone ve 43 T. lyra) incelenmiştir. Mide içeriklerindeki besin maddeleri yüzde sayısal varlık (\%n), yüzde bulunuş frekansı (\%f), ve yüzde baskınlık (\%d) olarak değerlendirilmiştir. Sonuçta, tüm türlerin diyetinde toplam 19 besin çeşidi belirlenmiş olup, Polychaeta, Crustacea, Mollusca, Echinodermata ve Teleostei olmak üzere beş temel besin grubu içinde sınıflandırılmıştır. Mide içeriği incelemeleri, tüm türler için genel besin tercihinin Crustacea'ler olduğunu göstermiştir

Anahtar kelimeler: Triglidae, mide içeriği, beslenme, Edremit Körfezi.

Food Preferences of the five gurnard species (Triglidae) in Edremit Bay

\section{Abstract}

In this study, the food composition of the five gurnard species (Chelidonichthys lucerna, Chelidonichthys lastoviza, Eutrigla gurnarduss, Lepidotrigla cavillone, Trigla lyra) from Edremit Bay (Aegean Sea), collected by trawl surveys in September 1999-August 2000, were investigated. A total of 1205 stomach contents (262 C. lucerna, 300 C. lastoviza, 300 E. gurnardus, $300 \mathrm{~L}$. cavillone and $43 \mathrm{~T}$. lyra) were analyzed. The percentage numerical abundance (n $\%$ ), percentage frequency of occurrence (f\%), and percentage dominance $(\mathrm{d} \%)$ prey types in the stomach contents were evaluated. Consequently, 19 food items were identified in the diet of all species and classified into five main categories: Polychaeta, Crustacea, Mollusca, Echinodermata and Teleostei. Stomach content analysis revealed that a common dietary preference for all species is Crustaceans.

Keywords: Triglidae, stomach contents, feeding, Edremit Bay.

\section{GİRIŞ}

Trofik ilişkiler hayvan topluluklarındaki biyolojik etkileşimleri anlamanın temelini oluşturur (Carrassón ve Cartes, 2002). Dolayısıyla, türlerin beslenmeleri ile ilgili bilgiler gerek balıkçılık yönetimi gerekse ekolojik ilişkilerin anlaşılması açısından son derece önemlidir.

Araştırma materyalimizi oluşturan Triglidae familyası dünya denizleri ve ülkemizde farklı araştırmalara konu olmuştur. Yapılan çalışmalar sonucunda bu familyaya ait Akdeniz'de sekiz (BenTuvia, 1953; Tortonese, 1975; Hureau, 1986; Fischer vd., 1987) Karadeniz'de ise üç (Slastenenko, 1955-1956) türün bulunduğu tespit edilmiştir.

Kırlangıç balıklarının biyolojisi üzerine yapılan çok sayıda çalışmanın yanısıra, familya üyelerinin beslenme özelliklerini içeren özellikle Akdeniz'de yapılmış çalışmalar mevcuttur (Froglia, 1976; Moreno ve Matallanas, 1983; Jardas ve Zupanovic, 1983; Caragitsou ve Papaconstantinou, 1990; de Gee ve Kikkert, 1993; Moreno-Amich, 1994; Caragitsou ve Papaconstantinou, 1994; Colloca vd., 1994; Morte vd., 1997; Labropoulou ve Machias, 1998; Serena vd., 1998; Tetrats vd., 2000; Weinert vd., 2010; Vallisneri vd., 2011; Stagioni vd., 2012; Vinogradov vd., 2014; Montanini vd., 2017). 
Ülkemiz denizlerinde ise bu familya türlerinin beslenme özellikleri ile ilgili çok az sayıda çalışma yer almaktadır (Toğulga vd., 2000; İçemer vd., 2002). Dolayısıyla, bu konudaki eksikliği gidermek ve Triglidae familyasının üçü ekonomik öneme sahip beş türünün (Chelidonichthys lucerna, Chelidonichthys lastoviza, Eutrigla gurnarduss, Lepidotrigla cavillone, Trigla lyra) Edremit Körfezi’ndeki besin kompozisyonlarını tespit etmek amacıyla bu çalışma gerçekleştirilmiştir.

\section{MATERYAL ve METOT}

Araştırma materyalimizi oluşturan Triglidae familyasının 5 türüne ait örnekler, Edremit Körfezi'nden ( $39^{\circ} 23^{\prime} 25^{\prime \prime} \mathrm{N}$ ve $39^{\circ} 33^{\prime} 00^{\prime \prime} \mathrm{N}$ ile $26^{\circ} 36^{\prime} 05^{\prime \prime} \mathrm{E}$ ve $26^{\circ} 55^{\prime} 01^{\prime \prime}$ E) Eylül 1999-Ağustos 2000 tarihleri arasında, bir yıl boyunca, aylık olarak yapılan trol çekimleri ile elde edilmiştir.

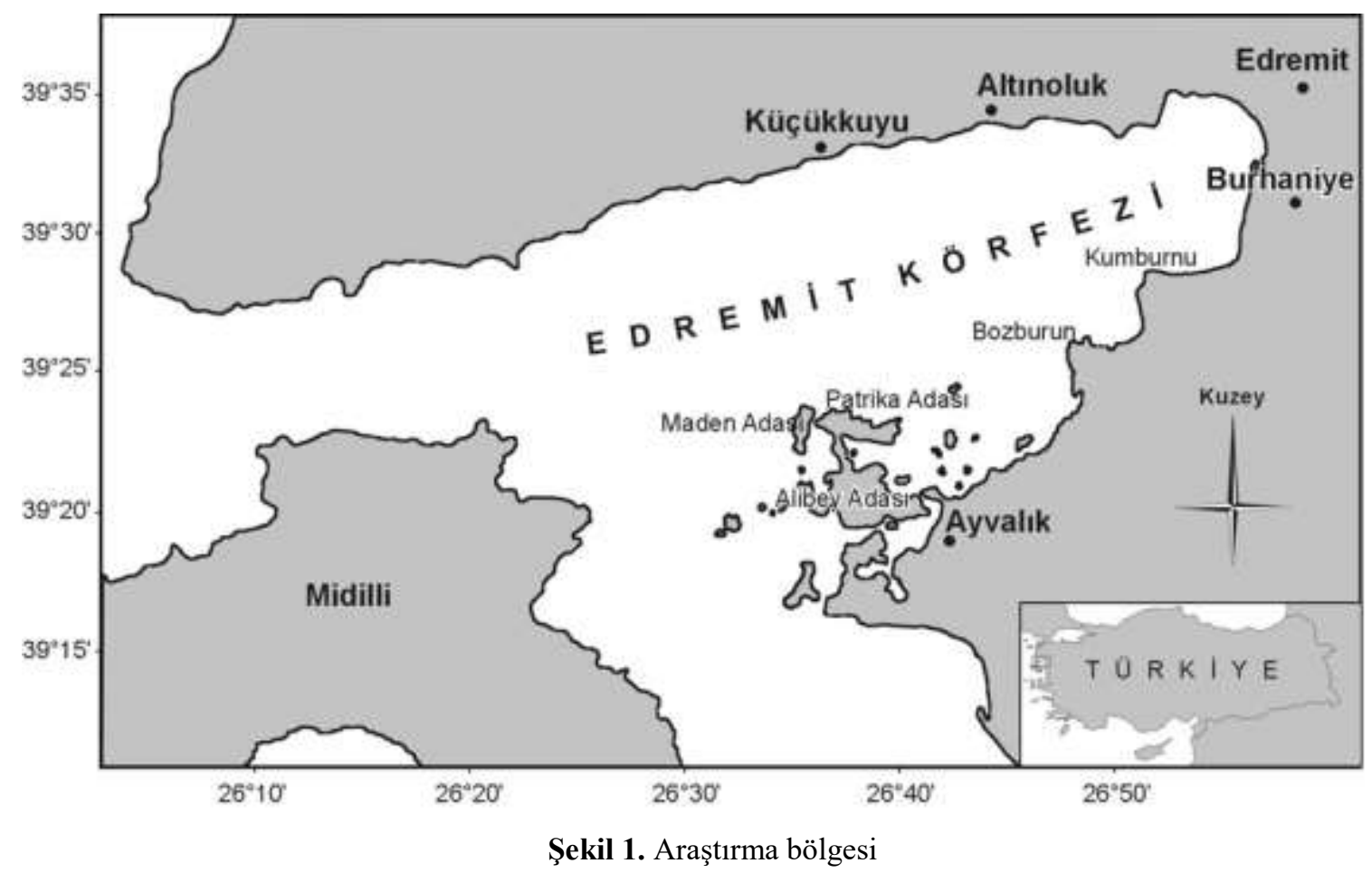

Yakalanan örneklerin çatal boy ölçümleri $1 \mathrm{~mm}$ hassasiyetli balık ölçme cetveli, vücut ve gonad ağırlığı ölçümleri ise $0,01 \mathrm{~g}$ hassasiyetli elektronik terazi ile yapılmıştır. Balıkların beslenme özelliklerini belirlemek amacıyla çıkarılan midelerden elde edilen içerikler, stereo mikroskop altında grup düzeyinde incelenmiştir. Midelerdeki organizmaların sayım işleminde sindirilmeyen vücut parçalarından yararlanılmıştır (Katağan vd., 1990).

Mide içeriklerinin değerlendirilmesinde, Sayısal Analiz Yöntemi (Sayısal Varlık (n), Bulunuş Frekansı (f) ve Baskınlık (d)) kullanılmıştır (Holden ve Raitt, 1974).

Sayısal Varlık Yöntemi: $(\%) \mathrm{n}=\mathrm{ni} / \Sigma \mathrm{n} * 100$

( $\mathrm{ni}=\mathrm{i}$ besin grubunun sayıs1, $\Sigma \mathrm{n}=$ Tüm besin gruplarının toplam sayısı).

Bulunuş Frekansı Yöntemi: $(\%) \mathrm{f}=\mathrm{fi} / \Sigma \mathrm{f} * 100$

( $\mathrm{fi}=\mathrm{i}$ besin grubunun frekans1, $\Sigma \mathrm{f}=$ Toplam dolu mide sayıs1).

Baskınlık Yöntemi: $(\%) \mathrm{d}=\mathrm{si} / \Sigma \mathrm{s} * 100$

( $\mathrm{si}=\mathrm{i}$ besin grubu bulunan mide sayısı, $\Sigma \mathrm{s}=$ Boş mideler de dahil olmak üzere toplam mide sayısı).

İncelenen türler arasında, besin kompozisyonu açısından benzerlik olup olmadığını tespit etmek amacıyla, "Biodiversity" programı kullanılarak, örneklerin mide içeriklerinde tespit edilen 6 temel besin maddesinin bulunuş frekansına göre "Bray-Curtis Benzerlik Katsayısı Matrisi" belirlenmiş ve elde edilen verilerle "Kümeleme Analizi" yapılmıştır (Washington, 1984). 


\section{BULGULAR}

Edremit Körfezi'nden örneklenen Triglidae familyasına ait beş türün (C. lucerna, C. lastoviza, E. gurnarduss, L. cavillone, $T$. lyra) çatal boy ve total ağırlık dağılımı değerleri ile incelenen mide ve boş mide sayıları Tablo 1'de verilmiştir.

Tablo 1. Edremit Körfezi'nden örneklenen C. lucerna, C. lastoviza, E. gurnarduss, L. cavillone ve T.lyra'ya ait bazı biyolojik parametreler

\begin{tabular}{lccccc}
\hline \hline & C. lucerna & C. lastoviza & E. urnardus & L. cavillone & T. lyra \\
\cline { 2 - 6 } Çatal boy(cm) & $11,3-36,4$ & $10,1-22,1$ & $8,5-22,4$ & $5,8-14,1$ & $19,7-29,8$ \\
Á̆ırık (g) & $12,10-522,00$ & $11,39-147,23$ & $6,1-98,0$ & $2,32-40,09$ & $61,24-218,03$ \\
İncelenen mide & 262 & 300 & 300 & 300 & 43 \\
Boș mide & 23 & 16 & 14 & 29 & 3 \\
\% boș mide & 8,78 & 5,34 & 4,67 & 9,67 & 6,98 \\
\hline \hline
\end{tabular}

Mide içeriği incelenen türlerin avladığı ana taksonlara ait besin analizleri ise Tablo 2'de özetlenmiştir. Buna göre, araştırma bölgesinden elde edilen 262 adet $C$. lucerna'nın mide içeriğinin incelenmesi sonucunda Crustacea'lerin bu türün temel besin grubunu oluşturduğu ve Teleostei'nin de 2. sırada yer aldığı tespit edilmiştir. Mollusca, Echinodermata ve Polychaeta da besin olarak tüketilen diğer gruplar olarak belirlenmiştir (Tablo 2).

Edremit Körfezi'nden elde edilen C. lastoviza, E. gurnardus ve L. cavillone örneklerinden rastgele seçilen 300 adedinin mide içeriklerinin incelenmesi ile bu üç türün de temel besin grubunu yine Crustacea'lerin oluşturduğu tespit edilmiştir. Mollusca, Teleostei ve Polychaeta ise alınan diğer besin grupları olarak saptanmıştır. Bu besin grupları L. cavillone türü için düşük oranlarda tercih edilen gruplar olarak belirlenmiştir (Tablo 2).

Tablo 2. C. lucerna, C. lastoviza, E. gurnarduss, L. cavillone ve T. lyra'nın mide içeriklerinde saptanan besin gruplarının sayısal varlık $(\% \mathrm{n})$, bulunuş frekansı $(\% \mathrm{f})$, ve baskınlık $(\% \mathrm{~d})$ oranları $(\mathrm{n}$; incelenen toplam mide say1s1)

\begin{tabular}{|c|c|c|c|c|c|c|c|c|c|c|c|c|c|c|c|}
\hline \multirow[b]{2}{*}{ Besin Grupları } & \multicolumn{3}{|c|}{$\begin{array}{c}\text { C. lucerna } \\
(\mathrm{n}=\mathbf{2 6 2})\end{array}$} & \multicolumn{3}{|c|}{$\begin{array}{l}\text { C. lastoviza } \\
(\mathrm{n}=\mathbf{3 0 0})\end{array}$} & \multicolumn{3}{|c|}{$\begin{array}{l}\text { E. gurnardus } \\
(\mathrm{n}=\mathbf{3 0 0})\end{array}$} & \multicolumn{3}{|c|}{$\begin{array}{l}\text { L. cavillone } \\
(\mathrm{n}=\mathbf{3 0 0})\end{array}$} & \multicolumn{3}{|c|}{$\begin{array}{l}\text { T. lyra } \\
(n=43)\end{array}$} \\
\hline & $\% n$ & $\% \mathbf{f}$ & $\% d$ & $\% n$ & $\% \mathbf{f}$ & $\% d$ & $\% n$ & $\% \mathbf{f}$ & $\% d$ & $\% \mathbf{n}$ & $\% \mathbf{f}$ & $\% d$ & $\%$ n & $\% \mathbf{f}$ & $\% d$ \\
\hline Polychaeta & 0,19 & 0,44 & 0,38 & 0,42 & 3,24 & 3,01 & 0,10 & 1,01 & 1.00 & 0,02 & 0,34 & 0,33 & 5,79 & 45,24 & 44,19 \\
\hline \multicolumn{16}{|l|}{ Crustacea } \\
\hline Mysidacea & 5,97 & 6,99 & 6,08 & 47,75 & 80,94 & 75,01 & 74,23 & 71,04 & 70,33 & 71,38 & 97,26 & 93,73 & 2,2 & 9,52 & 9,3 \\
\hline Cumacea & - & - & - & 0,29 & 2,52 & 2,33 & 0,10 & 1,35 & 1,33 & 3,01 & 20,89 & 20,13 & - & - & - \\
\hline Isopoda & 0,19 & 0,44 & 0,38 & 0,23 & 1,44 & 1,33 & - & - & - & 0,11 & 1,71 & 1,65 & - & - & - \\
\hline Amphipoda & 0,19 & 0,44 & 0,38 & 4,89 & 22,30 & 20,67 & 6,19 & 18,52 & 18,33 & 10,21 & 57,88 & 55,78 & - & - & - \\
\hline Decapoda & 0,58 & 1,31 & 1,14 & 7,19 & 32,01 & 29,67 & 11,83 & 40,74 & 40,33 & 8,11 & 38,36 & 36,96 & 0,28 & 2,38 & 2,33 \\
\hline Anomura & - & - & - & 9,08 & 30,22 & 28,00 & 0,38 & 3,03 & 3,00 & 0,36 & 3,42 & 3,30 & 3,86 & 19,05 & 18,6 \\
\hline Brachyura & 55,69 & 62,45 & 54,37 & 16,20 & 57,55 & 53,33 & 2,29 & 16,84 & 16,67 & 2,13 & 16,10 & 15,51 & 18,46 & 47,62 & 46,51 \\
\hline Stomatopoda & - & - & - & 0,16 & 1,44 & 1,33 & - & - & - & - & - & - & - & - & - \\
\hline \multicolumn{16}{|l|}{ Mollusca } \\
\hline Gastropoda & 3,08 & 6,11 & 5,32 & 0,45 & 2,88 & 2,67 & 0,21 & 2,69 & 2,67 & 0,02 & 0,34 & 0,33 & 56,75 & 71,43 & 69,77 \\
\hline Cephalopoda & 0,19 & 0,44 & 0,38 & 1,11 & 6,83 & 6,33 & 0,16 & 1,68 & 1,67 & - & - & - & - & - & - \\
\hline Scaphopoda & 0,19 & 0,44 & 0,38 & 0,01 & 0,00 & 0,00 & - & - & - & - & - & - & - & - & - \\
\hline Bivalvia & 6,94 & 10,92 & 9,51 & 0,98 & 5,76 & 5,33 & 0,34 & 2,02 & 2,00 & 0,02 & 0,34 & 0,33 & 0,83 & 7,14 & 6,98 \\
\hline \multicolumn{16}{|l|}{ Echinodermata } \\
\hline Asteroidea & 0,19 & 0,44 & 0,38 & - & - & - & - & - & - & - & - & - & 0,55 & 4,76 & 4,65 \\
\hline Ophiuroidea & - & - & - & - & - & - & - & - & - & - & - & - & 7,44 & 38,1 & 37,21 \\
\hline \multicolumn{16}{|l|}{ Teleostei } \\
\hline Tanımlanamayan Balık & 19,08 & 38,43 & 33,46 & 0,62 & 5,04 & 4,67 & 1,04 & 9,76 & 9,67 & 0,42 & 6,51 & 6,27 & 0,55 & 4,76 & 4,65 \\
\hline Balık larvası & 0,58 & 1,31 & 1,14 & 0,01 & 0,36 & 0,33 & 0,05 & 0,67 & 0,67 & - & - & - & - & - & - \\
\hline Balık yumurtası & - & - & - & 2,88 & 2,52 & 2,33 & 1,55 & 2,36 & 2,33 & - & - & - & - & - & - \\
\hline Tanımlanamayan organizma & 6,94 & 8,30 & 7,22 & 7,93 & 1,80 & 1,67 & 1,53 & 11,11 & 11.00 & 4,21 & 3,42 & 3,30 & 3,31 & 28,57 & 27,91 \\
\hline
\end{tabular}

Araştırma periyodu süresince körfezden $T$. lyra türüne ait sadece 43 birey yakalanabilmiş ve mide içerikleri incelenmiştir. Bu verilere göre, T. lyra'nın besininin büyük bölümünü sayısal varlık açısından Mollusca oluştururken, bulunuş frekansı ve baskınlık açısından Crustacea'nin de Mollusca 
ile eşit oranlarda tüketildiği saptanmıştır. Echinodermata, Polychaeta ve Teleostei'de besin olarak alınan diğer gruplar olarak tespit edilmiştir (Tablo 2).

Tablo 3. Beslenme açısından türler arasındaki "Bray-Curtis Benzerlik Katsayısı Matrisi"

\begin{tabular}{llllll}
\hline \hline & C. lucerna & T. lyra & L. cavillone & C. lastoviza & E. gurnardus \\
\hline C. lucerna & - & 54,87 & 65,73 & 67,93 & 71,17 \\
T. lyra & - & - & 46,97 & 54,20 & 50,44 \\
L. cavillone & - & - & - & 87,15 & 84,90 \\
C. lastoviza & - & - & - & - & 90,23 \\
E. gurnardus & - & - & - & - & - \\
\hline \hline
\end{tabular}

Beslenme rejimleri ayrı ayrı incelenen beş kırlangıç türü arasında besin kompozisyonu açısından benzerlik olup olmadığını belirlemek amacıyla "Bray-Curtis Benzerlik Katsayısı Matrisi" belirlenmiş ve bu verilere "Kümelenme Analizi" uygulanmıştır (Tablo 3 ve Şekil 2). İncelenen mide içeriklerinde tespit edilen 6 temel besin maddesinin midelerdeki bulunuş frekanslarına göre yapılan bu analiz sonucunda, araştırma bölgesindeki tüm Triglidae familyası türlerinin, Crustacea ilk sırada olmak üzere, benzer besin grupları üzerinden beslendiği saptanmıştır.
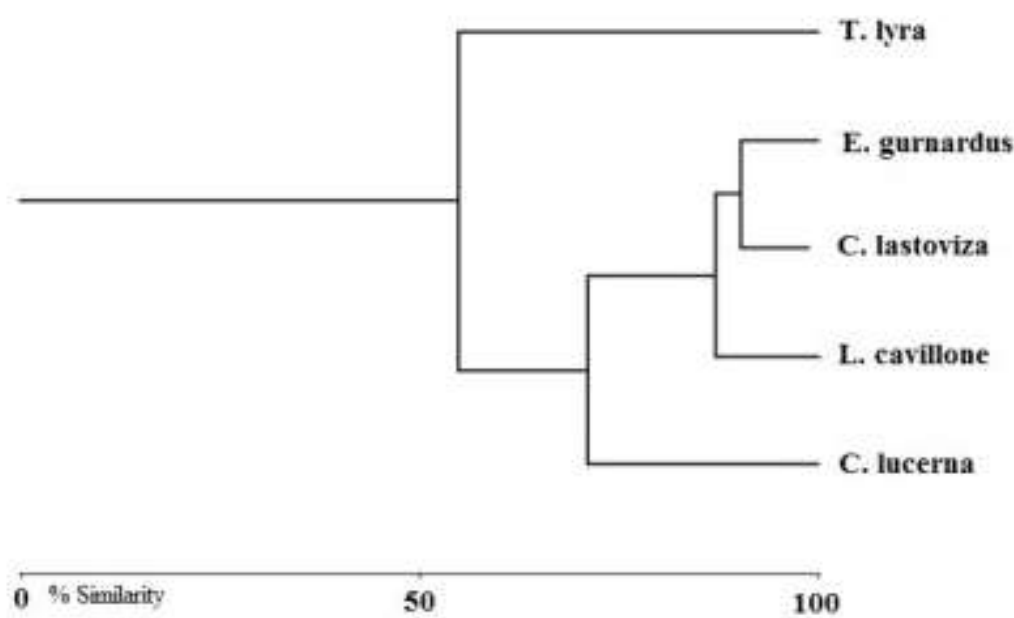

Şekil 2. Bray-Curtis Benzerlik Katsayısı Matrisi'ne göre beslenme açısından türler arasındaki "Kümelenme Analizi"

Özellikle E. gurnardus ile C. lastoviza türlerinin besin kompozisyonlarındaki benzerliğin çok yüksek olduğu (\% 90,23), T. lyra ve C. lucerna'nın ise diğer türlerden biraz farklı bir beslenme rejimi sergilediği gözlenmiştir. $\mathrm{Bu}$ iki tür, diğerlerine göre çok daha büyük boyutlara ulaşabilen türler olup, besin olarak tükettikleri organizmaların boyutları da, artan boylarına paralel olarak büyümektedir. Dolayısıyla, artan boyla birlikte, $C$. lucerna'da Teleostei'nin, T. lyra'da ise Mollusca ve Poychaeta tüketiminin artması, bu iki türün beslenme modelini, diğer türlerden farklılaştırmaktadır.

\section{TARTIŞMA ve SONUÇ}

Araştırma bölgemizden elde edilen toplam 1205 kırlangıç balığının mide içeriğinin incelenmesi sonucunda, Crustacea'lerin en fazla tüketilen besin grubunu oluşturduğu saptanmıştır. Crustacea'lerin kırlangıçların diyetindeki baskın rolü, farklı bölgelerde bu türlerin beslenmesini inceleyen birçok araştırı tarafından da rapor edilmiştir (Tablo 4).

Ayrıca çalışmamız sırasında, özellikle C. lastoviza ve E. gurnardus bireylerinin mide içeriklerinde bol miktarda Nematod (Aschelminthes) tespit edilmiştir. Ancak bu filum üyeleri parazit formlar olmaları sebebiyle, tüketilen besin grupları içerisine dahil edilmemiştir. Mide içeriklerinde çok miktarda Nematod'a rastlanılmasının, kırlangıç balıklarının parazitli balıklarla beslenmiş olabileceğinden kaynaklandığı düşünülmektedir. 
Tüm bu çalışmalara ait verilerde, sadece tüketilen besin gruplarının sıralamalarında değişimler gözlenmiştir. $\mathrm{Bu}$ da büyük olasılıkla, bu türler tarafından en çok tüketilen besin gruplarının farklı denizlerdeki genel dağılımları ve o bölgede bol olarak bulunmaları sebebiyledir.

$\mathrm{Bu}$ araştırma sonucuna göre Triglidae familyasına ait türlerin beslenme özelliklerinde gözlenen küçük değişimlerin, muhtemelen mevsimsel ve ortam farklılıkları ile tür içi veya türler arası ilişkilerden kaynaklandığ 1 düşünülmektedir. Genel olarak bakıldığında, beş türe ait bireylerin bölgede yeterli besini bularak iyi bir şekilde beslendiği tespit edilmiştir.

Tablo 4. C. lucerna, C. lastoviza, E. gurnarduss, L. cavillone ve T. lyra bireylerinin farklı bölgelere ait besin tercihleri

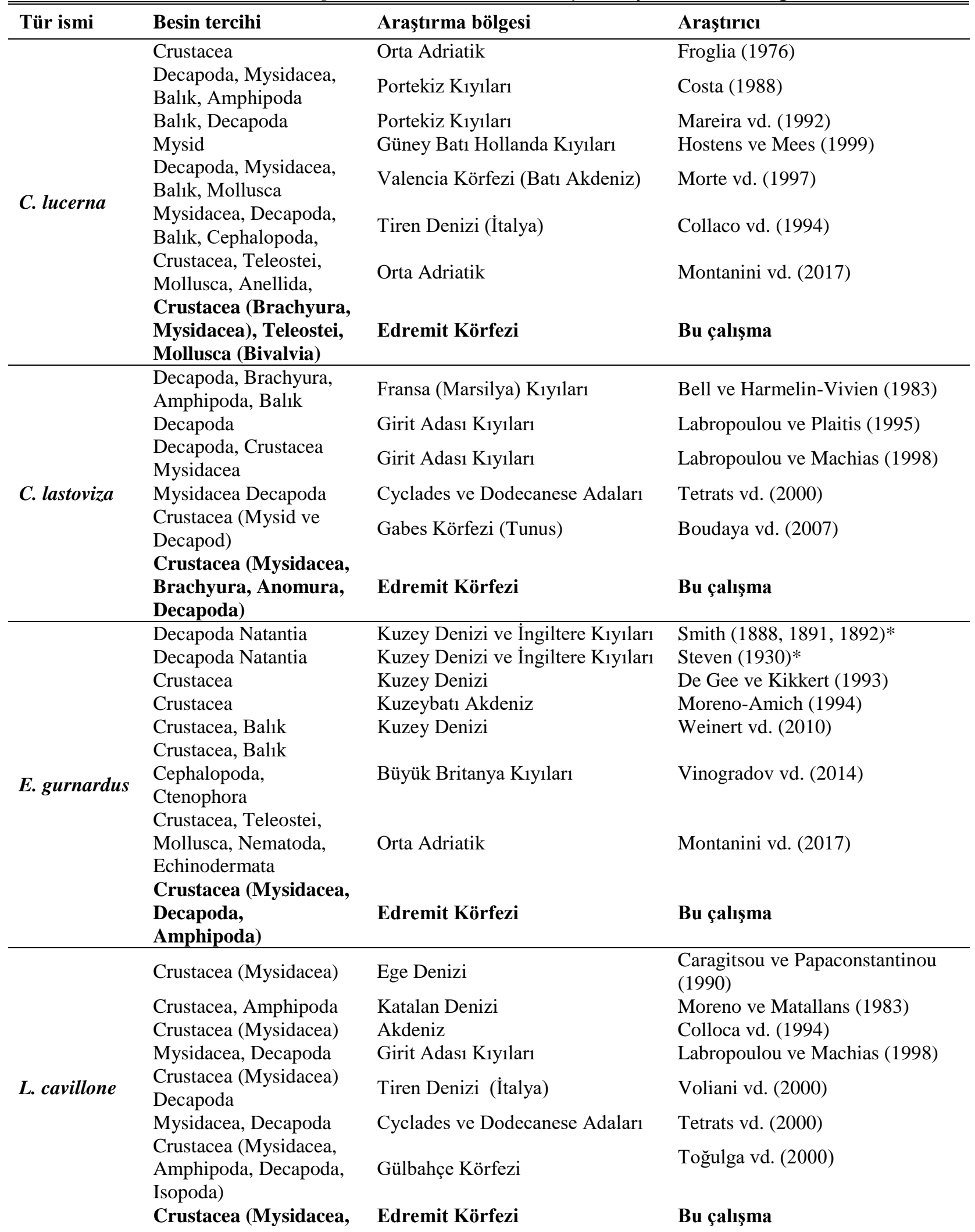




\begin{tabular}{|c|c|c|c|}
\hline & $\begin{array}{l}\text { Amphipoda, } \\
\text { Decapoda) }\end{array}$ & & \\
\hline \multirow{4}{*}{ T. lyra } & $\begin{array}{l}\text { Crustacea, } \\
\text { Echinodermata }\end{array}$ & Güney Adriatik & Jardas ve Zuponovic (1983) \\
\hline & $\begin{array}{l}\text { Mysidacea, Brachyura, } \\
\text { Decapoda }\end{array}$ & Saronikos Körfezi & $\begin{array}{l}\text { Caragitsou ve Papaconstantinou } \\
\text { (1994) }\end{array}$ \\
\hline & $\begin{array}{l}\text { Crustacea, Mollusca, } \\
\text { Echinodermata, Balık, } \\
\text { Polychaeta }\end{array}$ & Ege Denizi & İçemer vd. (2002) \\
\hline & $\begin{array}{l}\text { Mollusca } \\
\text { (Gastropoda), } \\
\text { Crustacea (Brachyura) }\end{array}$ & Edremit Körfezi & Bu çalışma \\
\hline
\end{tabular}

Teşekkür: Bu araştırma “Edremit Körfezi’nde Triglidae Familyasının (Kırlangıç Balıkları) Biyo-ekolojik Özelliklerinin Araştırılması" adlı Doktora Tezi’nin bir bölümünü içermektedir.

\section{KAYNAKLAR}

Bell, J.D., \& Harmelin-Vivien, M.L. (1983). Fish Fauna of French Mediterranean Posidonia Oceanica Seagrass Meadows. 2. Feeding Habits. Tethys, 11(1), 1-14.

Ben-Tuvia, A. (1953). Mediterranean fishes of Israel. Bulletin of the Sea Fisheries Research Station, Haifa, 8, 1-40.

Boudaya, L., Neifar, L., Taktak, A., Ghorbel, M., \& Bouain, A. (2007). Diet of Chelidonichthys obscurus and Chelidonichthys lastoviza (Pisces:Triglidae) from the Gulf of Gabes (Tunisia). Journal of Applied Ichthyology, 23(6), 646-653. doi: 10.1111/j.1439-0426.2007.00861.x

Caragitsou, E., \& Papaconstantinou, C. (1990). Food and feeding habits of large scale gurnard, Lepidotrigla cavillone (Triglidae) in Greek Seas. Cybium, 14(2), 95-104.

Caragitsou, E., \& Papaconstantinou, C. (1994). Feeding habits of piper Trigla lyra in the Saronikos Gulf (Greece). Journal of Applied Ichthyology, 10 (2-3), 104-113. doi:10.1111/j.1439-0426.1994.tb00149.x

Carrassón, M., \& Cartes, J.E. (2002). Trophic relationships in a Mediterranean deep-sea fish community: Partition of food resources, dietary overlap and connections within the benthic boundary layer. Marine Ecology Progress Series, 241, 41-55. doi:10.3354/meps241041

Colloca, F., Ardizzone, G.D., \& Gravina, M.F. (1994). Trophic ecology of gurnards (Pisces:Triglidae) in the Central Mediterranean Sea. Marine Life, 4(2), 45-57.

Costa, M.J. (1988). The Tagus and the Mira estuaries (Portugal) and their role as spawning and nursery areas. Journal of Fish Biology, 33, 249-250.

De Gee, A., \& Kikkert, A.H. (1993). Analysis of the grey gurnard (Eutrigla gurnardus) samples collected during the 1991 International Stomach Sampling Project. ICES C.M. 1993/G:14. 25 p.

Fischer, W., Scheider, M., \& Bauchot, M.L. (1987). Fiches FAO d'Identification des espéces pour les besoins dela péche. Mediterranée et Mer Noire, (Zone de péche 37), Vertèbrès, Vol. 2. FAO CEE, Rome, pp. 1406-1417.

Froglia, C. (1976). Osservazioni sull'alimentazione dei giovani di Trigla lucerna della classe di età nel Medio Adriatico Pisces, Triglidae). Archive of Oceanography and Limnology, 8, 365-373.

Hostens, K., \& Mees, J. (1999). The mysid-feeding guild of demersal fishes in the brackish zone of the Westerschelde estuary. Journal of Fish Biology, 55, 704-719.

Holden, M.J., \& Raitt, D.F.S. (eds.) (1974). Manual of fisheries science. Part 2: Methods of resource investigation and their application. FAO Fisheries Technical Report 115(Rev.1), Rome, Italy.

Hureau, J.C. (1986). Triglidae. In: Whitehead, P.J.P., Bauchot, M.-L., Hureau, J.-C., Nielsen, J., Tortonese, E. (eds.) Fishes of the north-eastern Atlantic and the Mediterranean. Vol. 3, UNESCO, Paris, pp. 1230-1238.

İçemer, A., Özaydın, O., Benli, H.A., \& Katağan, T. (2002). Feeding habits of Piper Trigla lyra (Linnaeus, 1758) inhabiting the Aegean Sea. Acta Adriatica, 43(2), 77-78.

Jardas, I., \& Zupanovic, S. (1983). Ishrana i neke druge karakteristike populacije lastavice, T. lyra, L., 1758, (Pisces: Triglidae) u podrucju juznojadranske kotline (crnogorsko primorje). Studia Marina, 13-14, 167-187.

Katağan, T., Kaya, M., Ergen, Z., \& Önen, M. (1990). İzmir Körfezi’nde yaşayan Mullus barbatus Linneaeus, 1758 türünün beslenme rejimi. Turkish Journal of Zoology, 14(2), 179-187.

Labropoulou, M., \& Plaitis, W. (1995). Selective predation on small crustaceans by six demersal fish species in Iraklion Bay (Cretan Sea, North-eastern Mediterranean). In: Eleftheriou, A., Ansel, A.D. \& Smith, C.J. (eds.) Biology and Ecology of Shallow Coastal Waters. Olsen and Olsen, Denmark, pp. 351-358.

Labropoulou, M., \& Machias, A. (1998). Effects of habitat selection on the dietary patterns of two triglid species. Marine Ecology Progress Series, 173, 275-288.

Mareira, F., Assis, C.A., Almeida, P., Costa, R., \& Costa, M.J., 1992, Trophic Relationships in the Community of the Upper Tagus Estuary (Portugal): a Preliminary Approach. Estuarine, Coastal and Shelf Science, 34, 617-623. 
Montanini, S., Stagioni, M., Benni, E., \& Vallisneri, M. (2017). Feeding strategy and ontogenetic changes in diet of gurnards (Teleostea: Scorpaeniformes: Triglidae) from the Adriatic Sea. The European Zoological Journal, 84, 356367. doi:10.1080/24750263.2017.1335357

Moreno, R., \& Matallanas, J. (1983). Etude du regime alimentaire de Lepidotrigla cavillone (Lacepede, 1801) (Pisces: Triglidae) dans la Mer Catalane. Cybium, 7(3), 93-103.

Moreno-Amich, R. (1994). Feeding habits of grey gurnard, Eutrigla gurnardus (L., 1758), along the Catalan Coast (Northwestern Mediterranean). Hydrobiologia, 273,57-66.

Morte, M.S., Redon, M.J., \& Sanz-Brau, A. (1997). Trophic relationships between two gurnards Trigla lucerna and Aspitrigla obscura from the Western Mediterranean. Journal of the Marine Biological Association of the United Kingdom 77, 527-537.

Serena, F., Voliani, A., \& Auteri, R. (1998). Nursery Areas and Some Biological Information of Tub Gurnard (Trigla lucerna L., 1758) off Tuscany Coasts (Italy). Rapp. Comm. Int. Mer. Me'dit., 35, 482-483.

Slastenenko, E. (1955-1956). Karadeniz Havzası Balıkları. Et Balık Kurumu Umum Müdürlüğü Yayınları, Cilt: I, İstanbul, $711 \mathrm{~s}$.

Stagioni, M., Montanini, S., \& Vallisneri, M. (2012). Feeding of tub gurnard Chelidonichthys lucerna (Scorpaeniformes: Triglidae) in the north-east Mediterranean. Journal of the Marine Biological Association of the United Kingdom, 92(3), 605-612. doi:10.1017/S0025315411000671

Stergiou, K.I., \& Karpouzi, V.S. (2002). Feeding habits and trophic levels of Mediterranean fish. Review in Fish Biology and Fisheries, 11, 217-254.

Tetrats, A., Petrakis, G., \& Papaconstantinou, C. (2000). Feeding habits of A. cuculus (L., 1758) (red gurnard), L. cavillone (Lac., 1802) (large scale gurnard) and T. lastoviza (Brunn., 1768) (rock gurnard) around Cyclades and Dodecanese Islands (E. Mediterranean). Mediterranean Marine Science, 1(1), 91-104.

Toğulga, M., Katağan, T., Akalın, S., \& Uçkun, D. (2000). Gülbahçe Körfezi’nde Kırlangıç Balığının (Lepidotrigla cavillone) (Lacepéde, 1801) Beslenme Rejimi. Ege Üniversitesi Su Ürünleri Dergisi, 17(3-4), 49-57.

Tortonese, E. (1975). Osteichthyes (Pesci Ossei). Parte Seconda. Fauna d'Italia. Calderini Bologna. 636 p.

Vallisneri, M., Stagioni, M., Montanini, S., \& Tommasini, S. (2011). Body size, sexual maturity and diet in Chelidonichthys lucerna (Osteichthyes: Triglidae) from the Adriatic Sea, north eastern Mediterranean. Acta Adriatica, 51(1), 141-148.

Vinogradov, V.I., Arkhipov, A.G., \& Kozlov, D.A. (2014). Feeding of Grey Gurnard Eutrigla gurnardus (Triglidae) in the Area of the Rockall Seamount. ISSN 0032_9452. Journal of Ichthyology, 54(3), 243-248 (Original Russian Text).

Weinert, M., Floeter, J., Kröncke I., \& Sell, A.F. (2010). The role of prey composition for the condition of grey gurnard (Eutrigla gurnardus). Journal of Applied Ichthyology, 26(1), 75-84.

Washington, H.G. (1984). Diversity, biotic and similarity indices: a review with special reference to aquatic systems. Water Resources, 18, 653-694.

Voliani, A., Manini, P., \& Auteri, R. (2000). Distribuzione e Biologia di L. cavillone (Lacepede, 1802) e L. dieuzeidei (Audoin in Blanc \& Hureau) Nell'arcipelago Toscano. Biologia Marina Mediterranea, 7(1), 844-849. 